\title{
Erratum to: Alien species along the Italian coasts: an overview
}

\author{
Anna Occhipinti-Ambrogi - Agnese Marchini - Grazia Cantone • \\ Alberto Castelli - Carla Chimenz - Mario Cormaci - Carlo Froglia • \\ Giovanni Furnari - Maria Cristina Gambi - Giuseppe Giaccone • \\ Adriana Giangrande - Cinzia Gravili - Francesco Mastrototaro • \\ Cristina Mazziotti • Lidia Orsi-Relini - Stefano Piraino
}

Published online: 1 September 2010

(C) Springer Science+Business Media B.V. 2010

\section{Erratum to: Biol Invasions DOI 10.1007/s10530-010-9803-y}

In the article: "Alien species along the Italian coasts: an overview" by Occhipinti-Ambrogi et al., appeared in Biol. Invasions (Published online: 02 July 2010)

The online version of the original article can be found under doi:10.1007/s10530-010-9803-y.

A. Occhipinti-Ambrogi $(\bowtie) \cdot$ A. Marchini DET-Dipartimento di Ecologia del Territorio, University of Pavia, Via S.Epifanio 14, 27100 Pavia, Italy e-mail: occhipin@unipv.it

G. Cantone

Dipartimento di Biologia Animale "M. La Greca", University of Catania, Via Androne 81, 95124 Catania, Italy

A. Castelli

Dipartimento di Biologia, University of Pisa,

Via Derna 1, 56126 Pisa, Italy

\section{Chimenz}

Dipartimento di Biologia Animale e dell'Uomo, University "La Sapienza" of Roma,

Viale Università 32, 00185 Rome, Italy

M. Cormaci · G. Furnari - G. Giaccone

Dipartimento di Botanica, University of Catania,

Via A. Longo 19, 95125 Catania, Italy

C. Froglia

CNR-ISMAR, Sede Ancona, Largo Fiera

della Pesca, 60125 Ancona, Italy
Table 1 contains a few errors. They are corrected below:

Hypnea cornuta: 2000 instead of 2002

Laurencia majuscula has to be removed

Lomentaria hakodatensis: 2000 instead of 2001

Branchiomma luctuosum: 1978-1979 instead of 1983

\section{C. Gambi}

Stazione Zoologica “Anton Dohrn”, Benthic Ecology Group, Villa Dohrn, Punta S. Pietro, 80077 Ischia, Napoli, Italy

A. Giangrande · C. Gravili · S. Piraino

CONISMA-Consorzio Nazionale Interuniversitario per le Scienze del Mare (ULR Lecce), DiSTeBA-Dipartimento di Scienze e Tecnologie Biologiche ed Ambientali, University of Salento, Via Provinciale Lecce-Monteroni, 73100 Lecce, Italy

F. Mastrototaro

Dipartimento di Biologia Animale ed Ambientale,

University of Bari, Via Orabona 4, 70125 Bari, Italy

C. Mazziotti

ARPA Emilia-Romagna, Struttura Oceanografica Daphne, Viale Vespucci 2, 47042 Cesenatico, FC, Italy

L. Orsi-Relini

DipTeRis-Dipartimento per lo studio del Territorio e delle sue Risorse, University of Genoa, Corso Europa 26, 16132 Genoa, Italy 
Megalomma claparedei: 1987 instead of 2008

Novafabricia infratorquata: 2000 instead of 2006

Ophryotrocha japonica: 1999 instead of 2002

Spirorbis marioni: 1977 instead of 1981

Haminoea japonica instead of Haminoea callidegenita

Paracartia grani instead of Acartia grani: 1997 instead of 1999

Acartia tonsa: 1987 instead of 1989

Elasmopus pectenicrus: 1980 instead of 1981
Paracerceis sculpta: 1981 instead of 1980

Glabropilumnus laevis instead of Heteropanope laevis

Since the indigenous macroalga Laurencia majuscula was erroneously included, in Fig. 1 the numbers of alien species should be diminished of a unit in the following Italian seas: Southern Tyrrhenian, Straits of Sicily and Sardinia sea. Also in Fig. 2 the total number of Macrophyta should be diminished of a unit. 